\begin{tabular}{l|c|c|}
\hline CilTKARA & Journal of Chemistry, Environmental Sciences \\
UNIVERSITY & and its Applications \\
\hline
\end{tabular}

\title{
Effect of Copper Substitution, Calcination Temperature, and Photo-sensitizers on Photocatalytic Activity of $\mathrm{Cu}_{0.05} \mathrm{Zn}_{0.95} \mathrm{O}$
}

Suyog A. Soni1*, Vikram R. Jadhav² and Tushar A. Kere ${ }^{3}$

${ }^{1}$ K. K. Wagh ACS college pimplus (Ramache), Nashik, 422 301, Maharashtra, India

${ }^{2}$ K. K. Wagh ACS college Pimpalgaon (B), Nashik, 422 209, Maharashtra, India

${ }^{3}$ K. K. Wagh ACS college Nashik, Nashik, 422 003, Maharashtra, India

"Email: suyogsoni1988@gmail.com

\section{ARTICLE INFORMATION}

Received: 22 July 2018

Revised: 13 August 2018

Accepted: 25 August 2018

Published Online: 06 September 2018

Keywords:

Calcination, Photocatalytic Activity, IR, FTIR

\section{ABSTRACT}

A successful series of $\mathrm{Cu}_{\mathrm{x}} \mathrm{Zn}_{1-\mathrm{x}} \mathrm{O}$ (variable $\mathrm{x}=0.05,0.1,0.15$ and 0.2 ) were characterized by thermogravimetric (TG-DTA), Fourier Transform Infra-Red (FTIR) spectroscopy, and X-ray Diffraction (XRD) techniques. The photocatalytic activity of prepared samples was accurately assessed by the photocatalytic decomposition of LASER dye in an aqueous solution under irradiation of solar light and was compared favourably to non-dope commercially available $\mathrm{ZnO}$ photo-catalyst. The effect of various parameters like the amount of a catalyst, the calcination temperature on photocatalytic activity is also studied. The direct effect of various photosensitizing salts like $\mathrm{NaCl}, \mathrm{Na}_{2} \mathrm{CO}_{3}$, and $\mathrm{Na}_{2} \mathrm{~S}_{2} \mathrm{O}_{3}$ on photocatalytic activity of $\mathrm{ZnO}$ and $\mathrm{Cu}_{0.05} \mathrm{Zn}_{0.95} \mathrm{O}$ was carefully studied.

\section{Introduction}

Photocatalytic treatment of chemical pollutants using semiconductors as the photocatalyst has been important method among advanced reaction techniques. Many published studies precisely on the photocatalytic activity of a semiconductors like $\mathrm{TiO}_{2} . \mathrm{TiO}_{2}$ and most of the other photo-catalysts can barely respond to UV irradiation [2] that takes up $4 \%$ of solar energy, which limits the practical application of photo-catalysts to broad extent. Since direct sunlight typically contains favorably nothing but $4 \%$ of Ultra-Violet (UV) light as compared to visible light which is $43 \%$ of unlimited solar energy hence use of $\mathrm{TiO}_{2}$ is largely impaired [2]. In recent years $\mathrm{ZnO}$ shows its unique applications in the optics, opto electronics, catalysis, pyro-electricity, and piezo-electricity. $\mathrm{ZnO}$ is one of the important photo-catalyst because of its unique and novel advantages, like non-toxicity, minimum price, and high photocatalytic activity [4]. However, the disadvantages of this catalyst is that its catalytic activity is still not enough for the commercial applications. An effective and practical approach to improve the photocatalytic activity is doping by adding some hetero elements, through the presence of doping metal ions in the $\mathrm{ZnO}$ crystalline matrix significantly affects the photocatalytic activity charge carrier recombination rate and interfacial electron-transfer rate [5]. Extensively speaking the metal ions used as a dopant are often the transition metal ions e.g., $\mathrm{Co}^{2+}, \mathrm{Mn}^{2+}, \mathrm{Mn}^{4+}$ etc. [6]. In the past several years, semiconductors of $\mathrm{ZnO}$ doped with narrow-band-gap metals [1], including Fe, W, Cd and $\mathrm{Ga}$ have been reported. Rhodamine as shown in figure no. 1. Fluorescein, coumarin, stilbene, umbelliferone, tetracene, malachite green and many other dyes are commonly used as LASER dye.

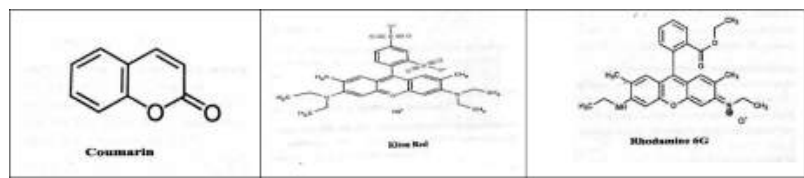

Figure 1. Structure of Coumarin, Kiton red, and Rodamine 6G.

The removal of LASER dye pollutants in waste water is an important measure in environment protection. Convention waste water treatment such as chemical, physical, biological process are not always suitable for treating moderate to high concentration waste water. Advanced Oxidation Process (AOPs) are alternative techniques for destruction of toxic compounds and many other dyestuff organics in waste 
water. The overall benefits of the delocalization of textile industrial waste water includes saving a huge amount of water, because textile industries, LASER dye industries are regarded as chemical intensive and water intensive. The decolorized effluent may be recycled in same industry and other applications like agriculture, other industries that required a less quality water, especially the suffer countries with water deficiency [10].

\section{Literature Survey}

A lot of work has been done on the removal and photocatalytic degradation of harmful dyes and organic compounds. The degradation is carried out by using sunlight as well as artificial UV sources. $\mathrm{TiO}_{2}$ and $\mathrm{ZnO}$ have good photocatalytic properties for photo-degradation of water pollutants including the good activity range of the solar radiation. $\mathrm{TiO}_{2}$ photo-catalysed degradation of phenol and o-substituted phenol compounds also investigated. Photo assisted dehalogenation and mineralization of chloro/ fluoro-benzoic acid derivatives in aqueous media using $\mathrm{TiO}_{2}$ is done. Removal of organic chlorine compounds by chemical action dehydrochlorination for the refinement of municipal waste plastic derived oil. Photo degradation of 3, 5, 6-trichloro-2-pyridinol in aqueous solution. Photo degradation of chlorinated pesticides dispersed on sand is also done.

\subsection{Nature of Problem}

The main purpose of the project is to degrade harmful laser dye compounds released from industries like textile industry and laser industries. LASER dyes are highly colored dye solution containing Kiton red, Rhodamine-6G, Coumarin, are shown in figure 1, Malachite green and others. These dyes are frequently utilized in LASER industries and these dye solution have to be replaced by fresh dye solution and it can't be directly discharged into water as effluent without treatment. These dyes contain large amount of organic matter which is highly toxic and carcinogenic, therefore very dangerously. The dye solution is stable and remains in the environment for longer periods. LASER dye solutions result in water pollution and this polluted water can penetrates through the soil and mixed with underground water, which is undesirable.

\section{Experimental Method}

\subsection{Materials}

In the present work, zinc nitrate hexahydrate [ $\mathrm{Zn}(\mathrm{NO} 3) 2.6 \mathrm{H} 2 \mathrm{O}]$, Copper (II) nitrate trihydrate
[Cu (NO3)2.3H2O], Oxalic acid [C2H2O4.2H2O] and Ethanol of Reagent grade obtained from Merck were used without purification.

\subsection{Procedure for Synthesis of Copper Doped Zinc Oxalate Precursors}

The co-precipitation method was used for synthesis of $\mathrm{Cu}$ doped $\mathrm{ZnO}$.

3.2.1 Zinc nitrate hexahydrate $(0.1 \mathrm{M})$, Copper nitrate tri-hydrate $(0.1 M)$ and ethanol in the proportion of (95:5:20) are mixed (solution: $A$ ),

\subsubsection{In round bottom flask Oxalic Acid (0.12M) $100 \mathrm{ml}$ was taken (Solution: B),}

3.2.3 Solution: A was added in Solution: B dropwise at room temperature with continuous stirring on magnetic stirrer within $1 \mathrm{hr}$. after total addition solution was further stirred for about $1 \mathrm{hr}$.

\subsubsection{Precipitate of Cux $\mathrm{Zn} 1-\mathrm{X}_{2} \mathrm{O}_{4}$ was filtered through whatman filter paper No. 42 and washed with distilled water and ethanol and dried at room temperature. Copper doped zinc oxalate precursor [(CuxZn1-XC2O4.YH2O); where $x=0.05,0.1,0.15$, 0.2 and $Y=2]$, were obtained in this way.}

\subsection{Characterizations of Precursor}

The characterization of precursor was done by using TGDTA and FTIR techniques.

\subsubsection{Characterization by TG-DTA Analysis}

Mass loss of substance is measured by thermogravimetric analysis as function of temperature. DTA used to study the thermal decomposition of precursor obtained in presence of air provides information about its thermal stability. The precursor CuxZn1-XC2O4 material was characterized by TG-DTA to find out the calcination temperature. Thermal decomposition of precursors was recorded on Matter TA 4000 instrument of Perkin-Elmer instrument.

\subsubsection{Characterization by FTIR}

IR spectra provides us full information about the molecular structure quickly. In this technique the majority cluster absorb characteristically inside definite vary. The shift 
within the position of absorption for specific teams with the modification in a molecule structure such as substitution or addition of a groups or an atoms in a molecule affects the relative mode of vibration of group resulting in to Change in band position, relative intensity $\&$ appearance of latest bands, splitting of single peaks into no. of peaks and the IR spectra of precursor were recorded within the region 4000$500 \mathrm{~cm}^{-1}$.

\subsection{Procedure for Synthesis of Copper Doped Zinc Oxide}

The previously synthesized precursor was calcined at $600{ }^{\circ} \mathrm{C}$ temperature in muffle furnace for $2 \mathrm{hr}$. to give $\mathrm{C}$ ux $\mathrm{Zn}{ }_{1-\mathrm{x}} \mathrm{O}$ (where, $\mathrm{x}=0.05,0.1,0.15 \& 0.2$ )

\subsection{Characterization of Copper Doped Zinc Oxide}

\subsubsection{Characterization by Chemical Analysis}

All synthesized CuxZn1-x C2O4 ( $\mathrm{x}=0.05,0.1,0.15$ and 0.2) was characterized by wet chemical methods, first sample was disintegrated by acid treatment. Then from the disintegrated samples $\mathrm{Zn}$ and $\mathrm{Cu}$ are separated by using group reagents. These separated metal compound solutions are diluted to known volume. Finally from these dilute solutions $\mathrm{Zn}$ was quantitatively determine by EDTA titration method using Erichrome Black $\mathrm{T}$ as indicator and $\mathrm{Cu}$ was determined by Iodometric method using Starch as indicator.

\subsubsection{Characterization by Powder XRD Studies}

The characterization of synthesized CuxZn1-xO samples was also done by using XRD (Model PW-1729) with auto divergent slit using $\mathrm{Cu} K \alpha$ radiation. The XRD pattern was used to determine the Inter planar distances (d). The d values obtained were compared with standard values of JCPDS data. The Interplanar distance (d), and diameter (D) of CuxZn1-x O samples were calculated by Bragg's law is shown in equation (1), and Scherrer equation is shown in equation (2) respectively.

According to Bragg's equation

$$
\mathrm{n} \lambda=2 \mathrm{~d} \sin \theta
$$

Where, $\mathrm{n}=1,2,3 \ldots$.

$\lambda=$ Wave length

$\mathrm{d}=$ Interplaner distance

$\theta=$ Glancing angle

According to Scherrer equation

$$
\mathrm{D}=\frac{0.89 \lambda}{\beta \cos \theta}
$$

Where, $\mathrm{D}=$ diameter (particle size)

$\mathrm{B}=\beta^{+} \pi / 180$

$\beta^{+}=$Full width at half maximum

$\lambda=$ Wave length

$\theta=$ Glancing angle

\subsubsection{Characterization by FTIR}

The IR spectra are shown in fig. 7 to 10 From the IR spectra the synthesis of copper doped zinc oxides was confirmed.

\subsection{General Mechanism of Photocatalytic Degradation}

The semiconductors ( $\mathrm{TiO} 2 \& \mathrm{ZnO}$ ) are good photo-catalyst, which shows photosensitivity, stability, and band gap used for the degradation of various environmental chemical contaminants. The photo-catalyst generates electron-hole pairs produced the empty conduction band leaving positive holes in valance band, which are capable of initiating a series of chemical reactions that eventually mineralized the pollutants. Many toxic chemicals can be degraded by this process. Moreover the formation of harmless eco-friendly end products represents another attractive features of this process as shown in figure no. 2 .

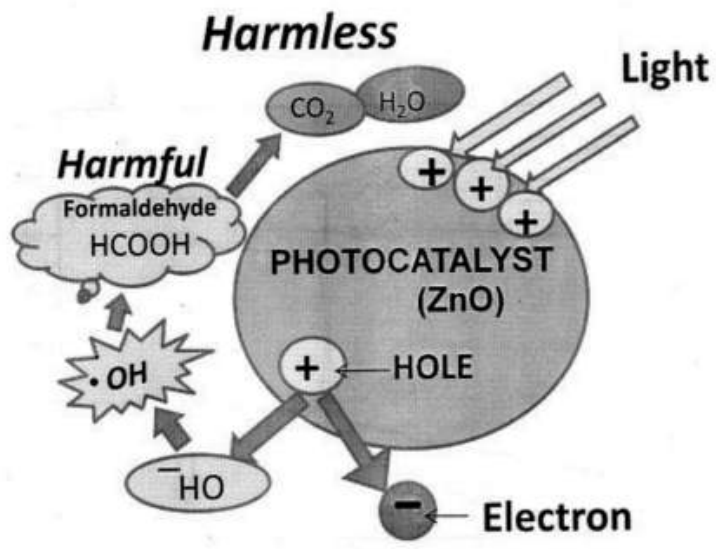

Figure 2. General mechanism of photocatalytic degradation

\subsection{Photocatalytic Degradation of Laser Dye Using Pure and Copper Doped Zinc Oxide}

Photocatalytic activity of CuxZn1-xO was determined by the photocatalytic degradation of dilute LASER dye solution $(10 \mathrm{~mL}$ dilute to $1000 \mathrm{~mL}$ ) was taken in a photocatalytic bath reactor. A known quantity of photo-catalyst CuxZn1-xO was 
added \& resulting reaction stirred magnetically obtaining uniform suspension in a photocatalytic bath reactor vessel. After irradiation in sunlight, the solution was filter through what-man filter paper No. 42. The clear solution obtain after filtration was used to measure its absorption on UVVisible Spectrophotometer-1601 SHIMADZU. Results are shown in Table no. 10, and Figure no. 19.

\section{Experimental Results \& Discussion}

\subsection{Characterization of Precursors}

\subsubsection{Characterization by TG-DTA analysis}

The TGA and DTA curves in the range of 25 to $800{ }^{\circ} \mathrm{C}$ are shown below is shown in figure no. 3 . The total weight loss was $56.50 \%$ and could be two distinct processes. Weight loss of approximately $18 \%$ occurred at $140{ }^{\circ} \mathrm{C}$ and could be attributed to the evaporation of surface water molecules on the particle surface. At $400{ }^{\circ} \mathrm{C}$, an additional observed weight reduction of approximately $38.50 \%$ was consistent with the decomposition oxalate molecules. No additional weight loss occurred above the decomposition temperature, indicating that the final decomposition products were copper doped zinc oxide.

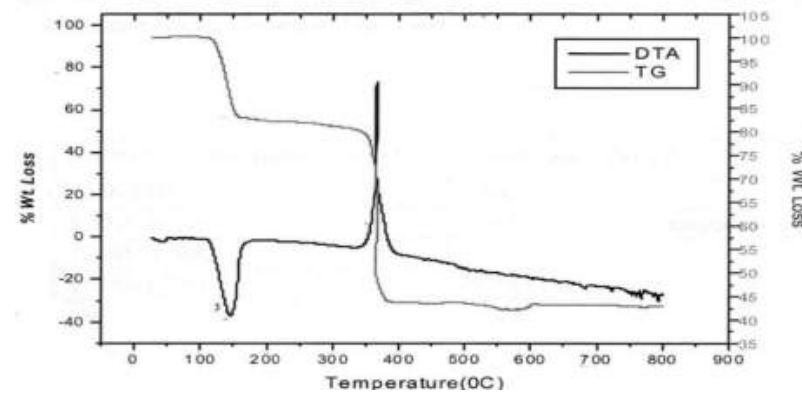

Figure 3. TGA and DTA curve

\section{Decomposition Reactions:}

STEP-I: $\mathrm{Cu}_{0.05} \mathrm{Zn}_{0.95} \mathrm{C}_{2} \mathrm{O}_{4} \cdot 2 \mathrm{H}_{2} \mathrm{O}----------\rightarrow \mathrm{Cu}_{0.05}$ $\mathrm{Zn}_{0.95} \mathrm{C}_{2} \mathrm{O}_{4}+2 \mathrm{H}_{2} \mathrm{O}$

STEP-II: $\mathrm{Cu}_{0.05} \mathrm{Zn}_{0.95} \mathrm{C}_{2} \mathrm{O}_{4}----------------\rightarrow \mathrm{Cu}_{0.05}$ $\mathrm{Zn}_{0.95} \mathrm{O}+\mathrm{CO}+\mathrm{CO} 2$

In this similar way the calcination temperature and weight loss were determined for the remaining compounds.

\subsubsection{Characterization of FTIR}

The IR spectra's of synthesized precursors shows prominent bands at $3600-3300 \mathrm{~cm}^{-1}$ may be due to water molecules, band at $1300-1200 \mathrm{~cm}^{-1}$ and $1700-1600 \mathrm{~cm}^{-1}$ may be due to characteristic band due to carbonyl $\mathrm{C}-\mathrm{O}$ and $\mathrm{C}=\mathrm{O}$ vibrational stretching frequency respectively. Also other bands at 560$450 \mathrm{~cm}^{-1}$ are due to $\mathrm{M}-\mathrm{O}$ vibrational stretching frequencies. (IR spectra are shown in Figure. No. 4 to 9 and 14 to 15)

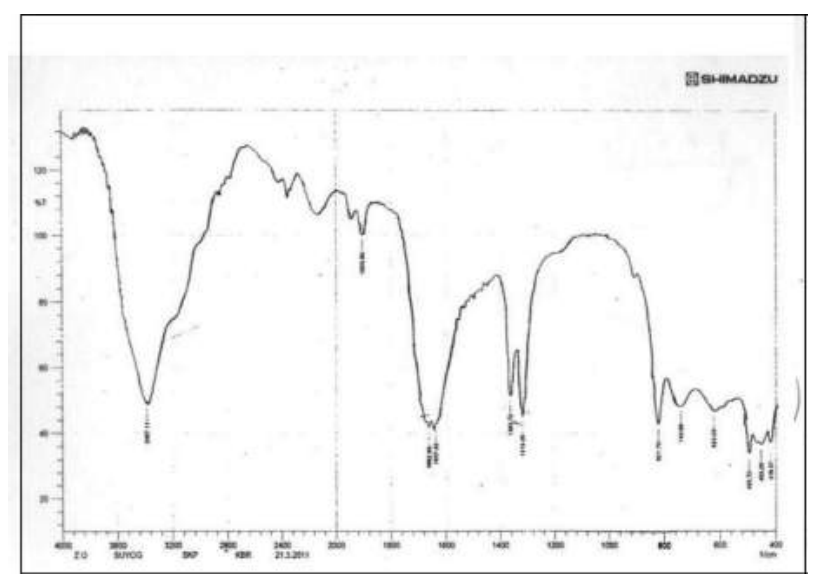

Figure 4. IR Spectra of the functional group

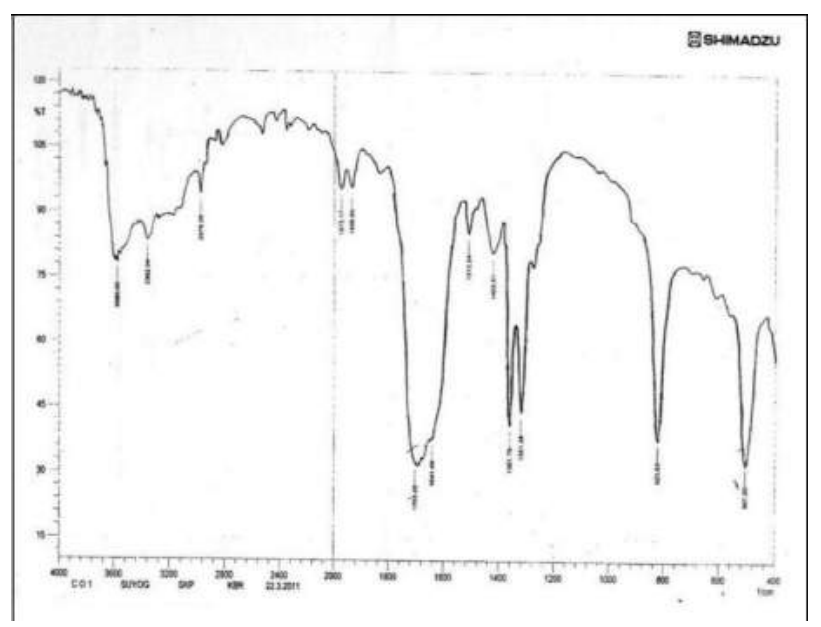

Figure 5. IR Spectra of the functional group

Table 1. IR Stretching frequency of the function group

\begin{tabular}{ll}
\hline Stretching frequency $(\mathrm{cm}-1)$ & Functional Group \\
\hline $560-450$ & $\mathrm{M}-\mathrm{O}$ \\
$3600-3300$ & $-\mathrm{OH}$ (or water molecule) \\
$1300-1200$ & $-\mathrm{O}-\mathrm{C}=\mathrm{O}$ \\
$1750-1650$ & $-\mathrm{C}=\mathrm{O}$ \\
\hline
\end{tabular}

\subsection{Characterization of Copper Doped Zinc Oxides}

All synthesized CuxZn1-Xc2o4 ( $\mathrm{x}=0.05,0.1,0.15,0.2)$ was characterized by wet chemical method, first sample was 
disintegrated by acid treatment. Then from the disintegrated samples $\mathrm{Zn}$ and $\mathrm{Cu}$ are separated by using group reagents. These separated metal compound solutions are diluted to know volume. Finally from this dilute solution $\mathrm{Zn}$ was quantitatively determine by EDTA titration method and $\mathrm{Cu}$ was determined by Iodometric method. The result obtained is shown in Table No. 2.

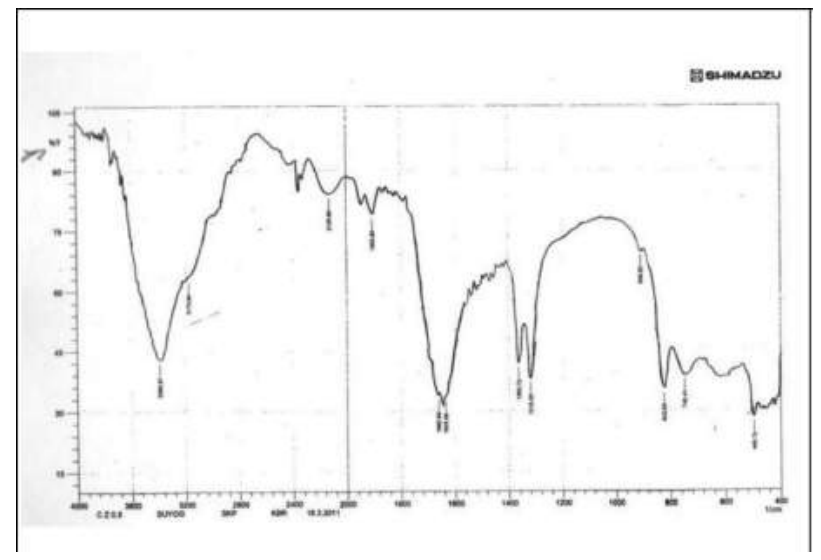

Figure 6. IR Spectra of the functional group

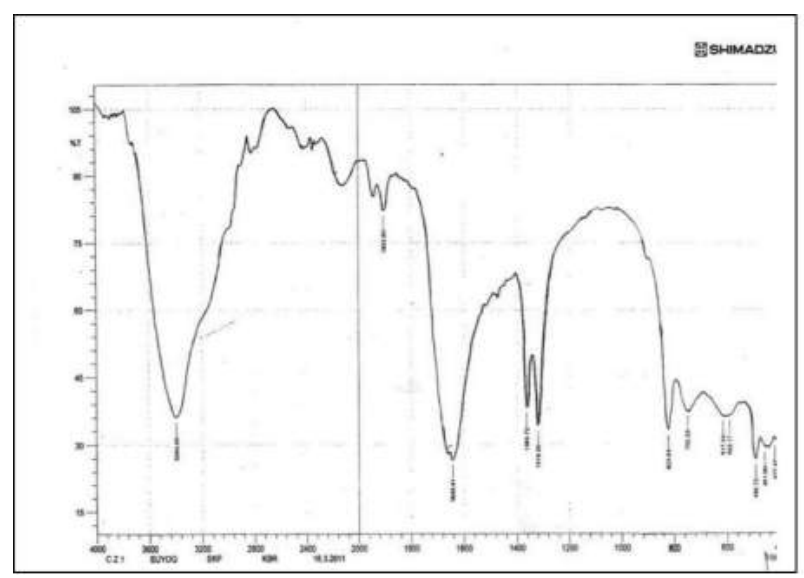

Figure 7. IR Spectra of the functional group

Table 2. Results of Chemical analysis

\begin{tabular}{llll}
\hline No. & Compound & $\begin{array}{l}\text { \% Theoretical } \\
\text { Value }\end{array}$ & $\begin{array}{l}\text { \% Experimental } \\
\text { Value }\end{array}$ \\
\hline \multirow{2}{*}{1} & $\mathrm{Cu} 0.05 \mathrm{Zn} 0.95 \mathrm{O}$ & $\mathrm{Cu}=3.91$ & $\mathrm{Cu}=3.82$ \\
& & $\mathrm{Zn}=76.42$ & $\mathrm{Zn}=74.85$ \\
\multirow{2}{*}{2} & $\mathrm{Cu} 0.1 \mathrm{Zn} 0.9 \mathrm{O}$ & $\mathrm{Cu}=7.83$ & $\mathrm{Cu}=7.84$ \\
& & $\mathrm{Zn}=72.48$ & $\mathrm{Zn}=71.92$ \\
\multirow{2}{*}{3} & $\mathrm{Cu} 0.15 \mathrm{Zn} 0.85 \mathrm{O}$ & $\mathrm{Cu}=11.75$ & $\mathrm{Cu}=11.60$ \\
& & $\mathrm{Zn}=68.53$ & $\mathrm{Zn}=68.71$ \\
\multirow{2}{*}{4} & $\mathrm{Cu} 0.2 \mathrm{Zn} 0.8 \mathrm{O}$ & $\mathrm{Cu}=15.69$ & $\mathrm{Cu}=15.21$ \\
& & $\mathrm{Zn}=64.57$ & $\mathrm{Zn}=68.97$ \\
\hline
\end{tabular}

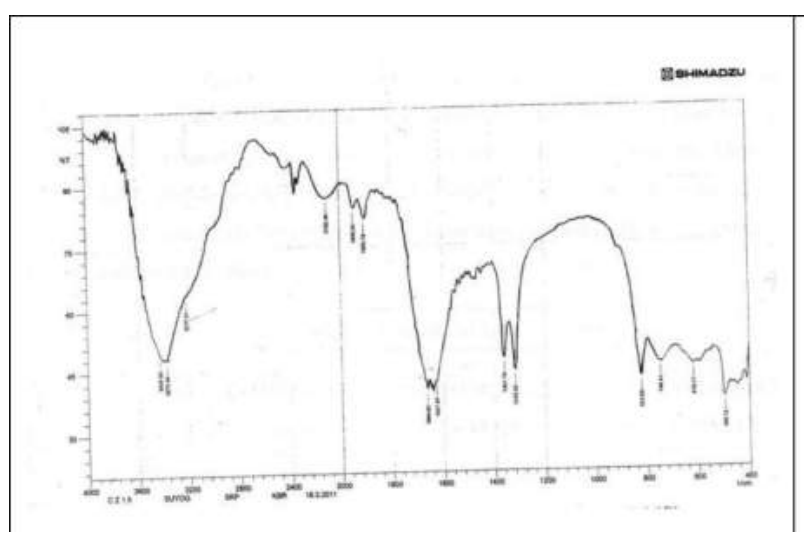

Figure 7. IR Spectra of the functional group

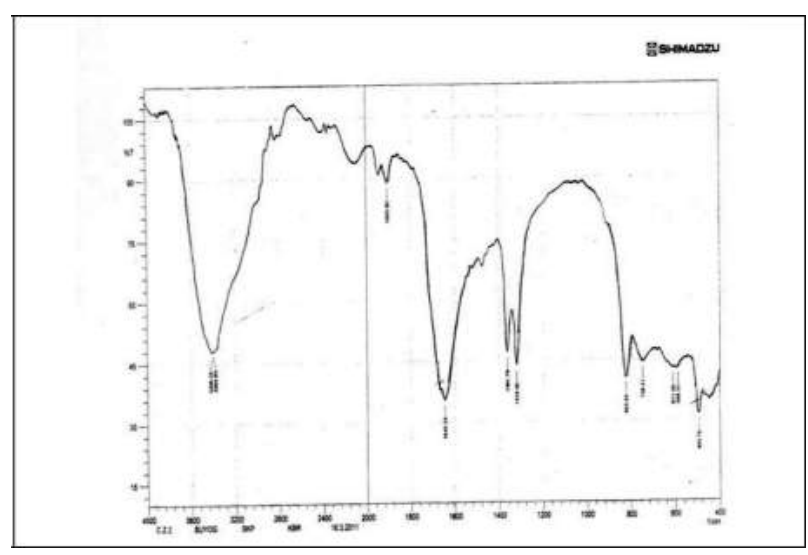

Figure 7. IR Spectra of the functional group

\subsubsection{Characterization by powder XRD studies}

The XRD patterns of CuxZn1-Xc2o4 ( $x=0.05,0.1,0.15$, 0.2 ) are shown below. The XRD pattern matches with the JCPDS ID-1451. The d-spacing values are calculated by using Bragg's equation and the result are summarized in Table No. 3 to 6 .

Table 3. XRD data of $\mathrm{Cu}_{0.05} \mathrm{Zn}_{0.95} \mathrm{O}$

\begin{tabular}{llllll}
\hline $\mathbf{2} \theta$ & \multirow{2}{*}{$\boldsymbol{\theta}$} & $\begin{array}{l}\mathbf{I} / \mathbf{I} \mathbf{0} \\
{ }_{\mathbf{0}} \mathbf{1 0 0}\end{array}$ & $\begin{array}{l}\text { Observed } \\
\text { 'd' spacing }\end{array}$ & $\begin{array}{l}\text { Standard JCPDS } \\
\text { 'd' spacing }\end{array}$ & $\mathbf{h} \mathbf{k} \mathbf{~}$ \\
\hline 31.8 & 15.9 & 57.95 & 2.8117 & 2.8143 & 100 \\
34.4 & 17.2 & 48.13 & 2.6049 & 2.6033 & 002 \\
36.2 & 18.1 & 100.00 & 2.4794 & 2.4759 & 101 \\
47.6 & 23.8 & 23.07 & 1.9088 & 1.9111 & 102 \\
56.6 & 28.3 & 38.93 & 1.6248 & 1.6247 & 110 \\
62.9 & 31.45 & 32.20 & 1.4764 & 1.4771 & 103 \\
68.0 & 34.00 & 27.42 & 1.3775 & 1.3781 & 112 \\
77.1 & 38.55 & 5.57 & 1.2360 & 1.2380 & 202 \\
\hline
\end{tabular}




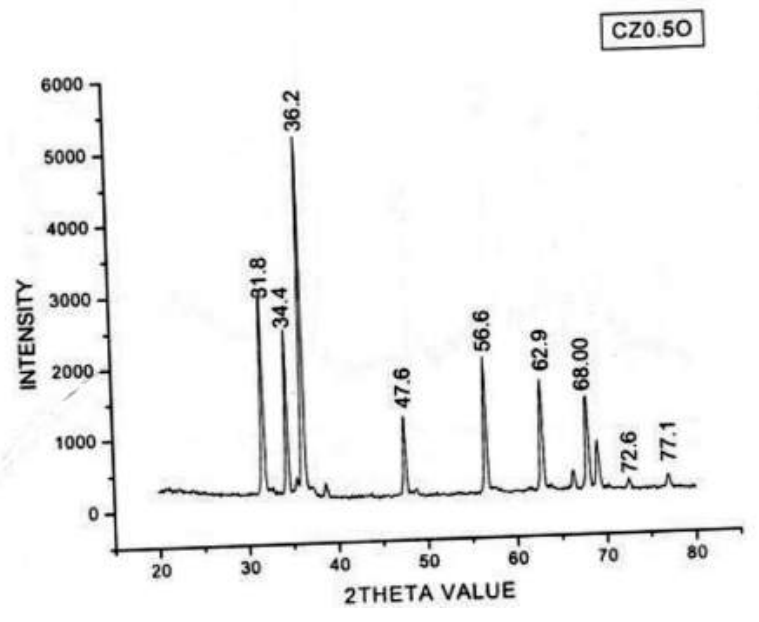

Figure 10. $\mathrm{XRD}$ of $\mathrm{Cu}_{0.05} \mathrm{Zn}_{0.95} \mathrm{O}$

Table 4. XRD data of $\mathrm{Cu}_{0.1} \mathrm{Zn}_{0.9} \mathrm{O}$

\begin{tabular}{llllll}
\hline $\mathbf{2} \theta$ & $\theta$ & $\begin{array}{l}\mathbf{I} / \mathbf{I} 0 \\
{ }^{100}\end{array}$ & $\begin{array}{l}\text { Observed } \\
\text { 'd' spacing }\end{array}$ & $\begin{array}{l}\text { Standard JCPDS } \\
\text { 'd' spacing }\end{array}$ & $\mathbf{h ~ k ~ \mathbf { ~ }}$ \\
\hline 31.7 & 15.75 & 60.20 & 2.8378 & 2.8143 & 100 \\
34.4 & 17.2 & 55.15 & 2.6049 & 2.6033 & 002 \\
36.3 & 18.1 & 100.00 & 2.4728 & 2.4759 & 101 \\
47.6 & 23.8 & 47.70 & 1.9088 & 1.9111 & 102 \\
56.6 & 28.3 & 70.50 & 1.6248 & 1.6247 & 110 \\
62.9 & 31.45 & 69.08 & 1.4764 & 1.4771 & 103 \\
68.0 & 34.00 & 62.61 & 1.3775 & 1.3781 & 112 \\
77.0 & 38.50 & 28.18 & 1.2374 & 1.2380 & 202 \\
\hline
\end{tabular}

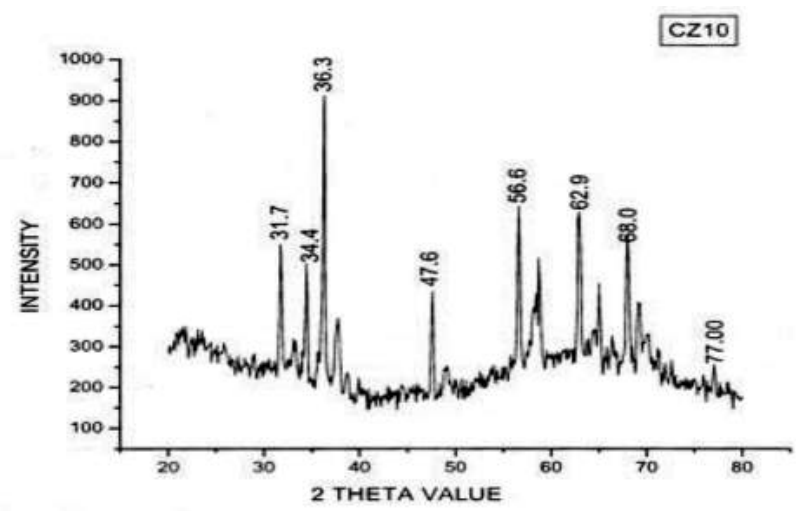

Figure. 11. $\mathrm{XRD}$ of $\mathrm{Cu}_{0.1} \mathrm{Zn}_{0.9} \mathrm{O}$

Table 5. XRD data of $\mathrm{Cu}_{0.15} \mathrm{Zn}_{0.85} \mathrm{O}$

\begin{tabular}{llllll}
\hline \multirow{2}{*}{$\theta$} & \multirow{2}{*}{$\theta$} & $\begin{array}{l}\mathbf{I} / \mathbf{I} 0 \\
{ }_{*} \mathbf{1 0 0}\end{array}$ & $\begin{array}{l}\text { Observed } \\
\text { 'd' spacing }\end{array}$ & $\begin{array}{l}\text { Standard JCPDS } \\
\text { 'd' spacing }\end{array}$ & $\mathbf{h} \mathbf{k} \mathbf{1}$ \\
\hline 31.8 & 15.90 & 60.79 & 2.9016 & 2.8143 & 100
\end{tabular}

\begin{tabular}{llllll}
34.4 & 17.20 & 47.83 & 2.6049 & 2.6033 & 0 \\
36.3 & 18.15 & 100.00 & 2.4728 & 2.4759 & 101 \\
47.5 & 23.75 & 22.97 & 1.8679 & 1.9111 & 102 \\
56.6 & 28.30 & 36.82 & 1.6248 & 1.6247 & 110 \\
62.9 & 31.45 & 29.15 & 1.4764 & 1.4771 & 103 \\
68.0 & 34.00 & 62.61 & 1.3775 & 1.3781 & 112 \\
77.0 & 38.50 & 5.68 & 1.2374 & 1.2380 & 202 \\
\hline
\end{tabular}

CZ1.50

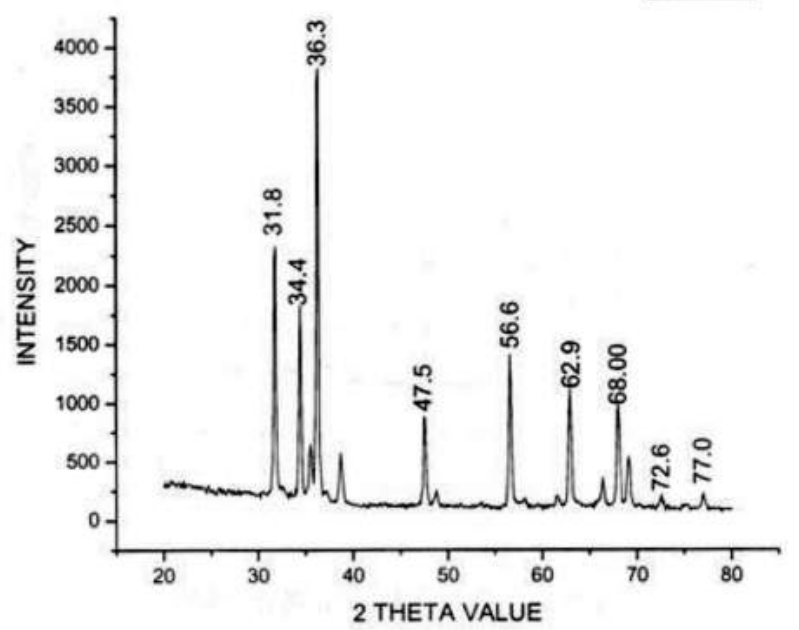

Figure 12. $\mathrm{XRD}$ of $\mathrm{Cu}_{0.15} \mathrm{Zn}_{0.85} \mathrm{O}$

Table 6. XRD data of $\mathrm{Cu}_{0.2} \mathrm{Zn}_{0.8} \mathrm{O}$

\begin{tabular}{llllll}
\hline \multirow{2}{*}{$\theta$} & $\theta$ & $\begin{array}{l}\text { I/I0 } \\
* \mathbf{1 0 0}\end{array}$ & $\begin{array}{l}\text { Observed } \\
\text { 'd' spacing }\end{array}$ & $\begin{array}{l}\text { Standard JCPDS } \\
\text { 'd' spacing }\end{array}$ & $\mathbf{h} \mathbf{k} \mathbf{~}$ \\
\hline 31.8 & 15.90 & 58.58 & 2.9016 & 2.8143 & 100 \\
34.4 & 17.20 & 44.20 & 2.6049 & 2.6033 & 002 \\
36.3 & 18.15 & 100.00 & 2.4728 & 2.4759 & 101 \\
47.6 & 23.80 & 23.83 & 1.9088 & 1.9111 & 102 \\
56.6 & 28.30 & 35.63 & 1.6248 & 1.6247 & 110 \\
62.9 & 31.45 & 32.64 & 1.4764 & 1.4771 & 103 \\
68.0 & 34.00 & 28.95 & 1.3775 & 1.3781 & 112 \\
77.0 & 38.50 & 6.73 & 1.2374 & 1.2380 & 202 \\
\hline
\end{tabular}

The average particle size (D) for all samples was calculated by using Scherrer equation. The results are summarized in Table: 6.

Table 7. Particle size by XRD pattern

\begin{tabular}{lll}
\hline No. & Compounds & Particle size (D) in $\mathbf{n m}$ \\
\hline 1. & $\mathrm{Cu}_{0.05} \mathrm{Zn}_{0.95} \mathrm{O}$ & 233.62 \\
2. & $\mathrm{Cu}_{0.1} \mathrm{Zn}_{0.9} \mathrm{O}$ & 150.32
\end{tabular}


3. $\mathrm{Cu}_{0.15} \mathrm{Zn}_{0.85} \mathrm{O} \quad 250.53$

4. $\quad \mathrm{Cu}_{0.2} \mathrm{Zn}_{0.8} \mathrm{O} \quad 275.58$

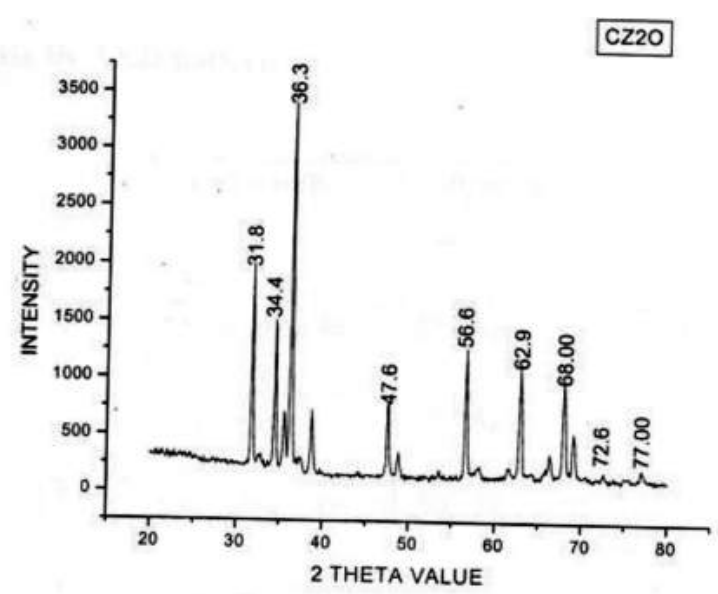

Figure 13. XRD of $\mathrm{Cu}_{0.2} \mathrm{Zn}_{0.8} \mathrm{O}$

\subsubsection{Characterization by FTIR}

From the IR spectra are shown in fig. 14 to 17 . From the IR spectra's of synthesized copper doped zinc oxides it is seen that the band at $3600-3300 \mathrm{~cm}^{-1}, 1750-1650 \mathrm{~cm}^{-1}$ and $1300-1200 \mathrm{~cm}^{-1}$ which was seen in IR spectra's of synthesized precursors are not seen. This indicates that the organic moiety is loosed completely to form $\mathrm{M}-\mathrm{O}$ bond. But in all oxides spectra's band at $550-450 \mathrm{~cm}^{-1}$ was seen, which are characteristic of $\mathrm{M}-\mathrm{O}$ vibrational stretching frequency, indicating that final products was copper doped zinc oxides.

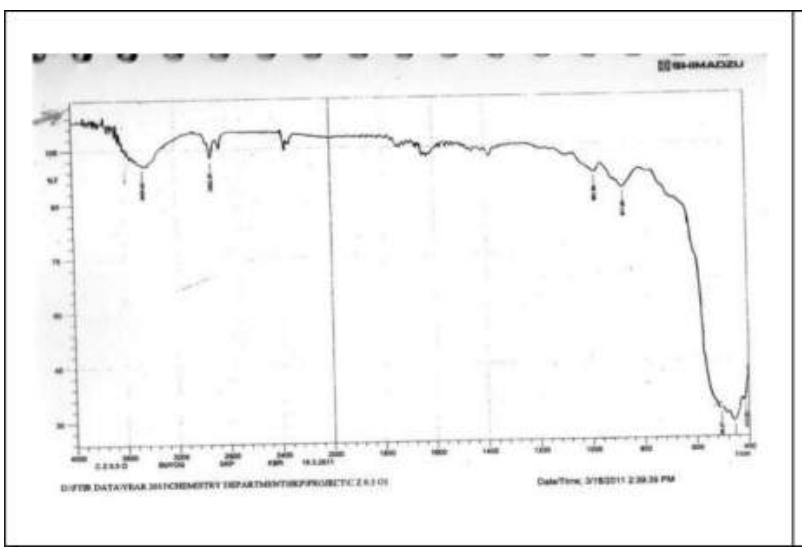

Figure 14.

The M-O vibrational stretching frequency for all compounds are summarized in following table.

\begin{tabular}{ll}
\hline Stretching frequency $(\mathbf{c m}-\mathbf{1})$ & Functional group \\
\hline $550-450$ & M-O \\
\hline
\end{tabular}

In comparison with pure $\mathrm{ZnO}$ IR spectra, the bands of copper doped zinc oxide spectra are slightly shifted this indicates that the copper was doped in $\mathrm{ZnO}$.

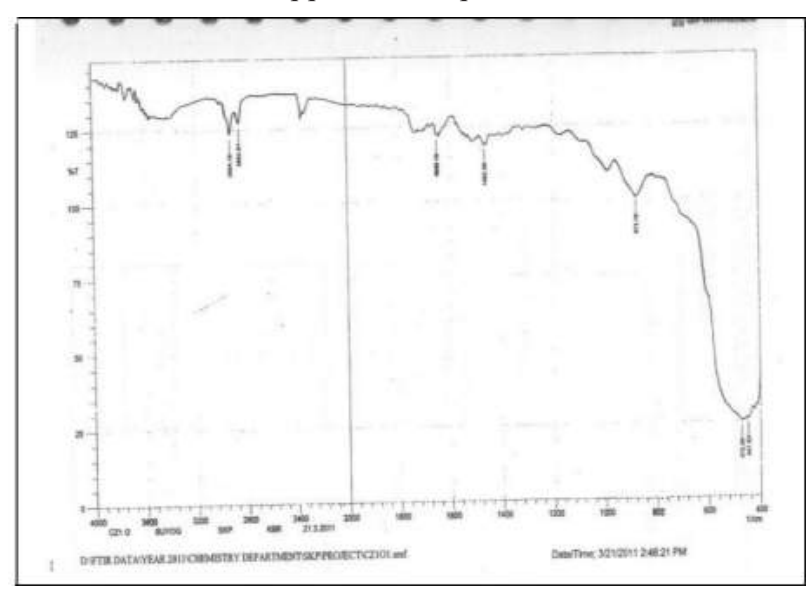

Figure 15 .

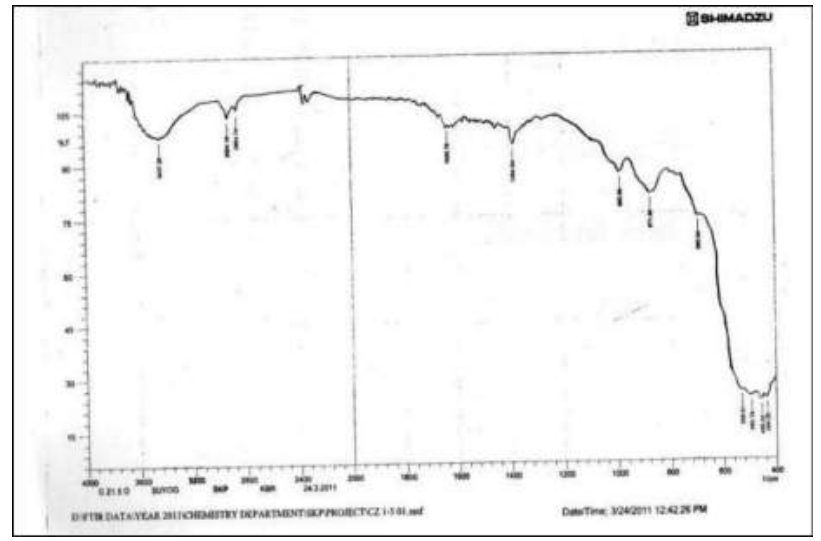

Figure 16.

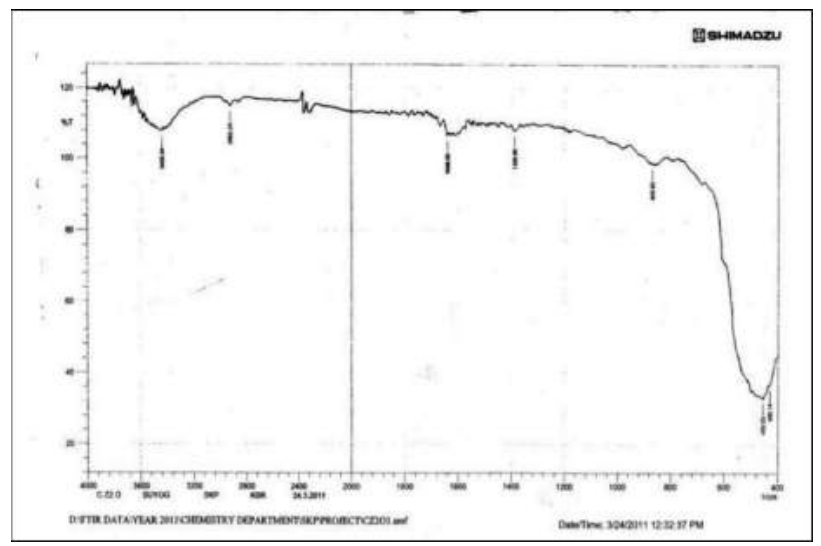

Figure 17.

4.3 Photocatalytic Degradation of LASER dye Using Pure and Copper Doped Zinc Oxide

The photocatalytic degradation of LASER dye using pure and copper doped zinc oxide is done in triplet. The average 
results are summarized in Table No. 8 and bar graph is shown in Figure No. 18.

Table 8. Results of photocatalytic activity by degradation of LASER

\begin{tabular}{lllll}
\hline $\begin{array}{l}\text { Volume of } \\
\text { LASER dye } \\
\text { solution }(\mathbf{m L})\end{array}$ & Compounds & $\begin{array}{l}\text { Amount } \\
(\mathbf{m g})\end{array}$ & $\begin{array}{l}\text { Irradiation } \\
\text { time (hrs.) }\end{array}$ & $\begin{array}{l}\% \\
\text { Degradation } \\
\text { Efficiency }\end{array}$ \\
\hline 100 & $\mathrm{ZnO}$ & 250 & 4 & $48.33 \%$ \\
100 & $\mathrm{Cu}_{0.05} \mathrm{Zn}_{0.95} \mathrm{O}$ & 250 & 4 & $64.13 \%$ \\
100 & $\mathrm{Cu}_{0.1} \mathrm{Zn}_{0.9} \mathrm{O}$ & 250 & 4 & $59.65 \%$ \\
100 & $\mathrm{Cu}_{0.15} \mathrm{Zn}_{0.85} \mathrm{O}$ & 250 & 4 & $53.93 \%$ \\
100 & $\mathrm{Cu}_{0.2} \mathrm{Zn}_{0.8} \mathrm{O}$ & 250 & 4 & $47.55 \%$ \\
\hline
\end{tabular}

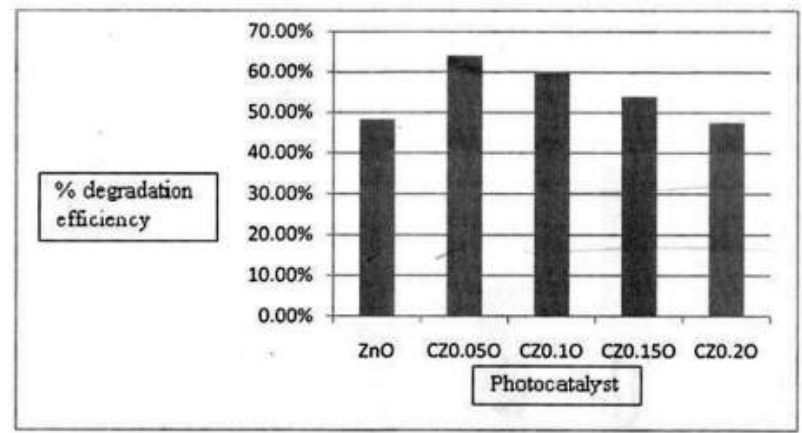

Figure 18. Results of photocatalytic activity by the degradation of LASER dye.

Table 9. Effect of calcination temperatures on the degradation of LASER dye solution.

\begin{tabular}{llllll}
\hline $\begin{array}{l}\text { Volume of LASER } \\
\text { dye solution }(\mathbf{m L})\end{array}$ & Photo-catalyst & $\begin{array}{l}\text { Calcination } \\
\text { Temperature (0C) }\end{array}$ & Amount (mg) & $\begin{array}{l}\text { Irradiation } \\
\text { Time (hrs) }\end{array}$ & $\begin{array}{l}\text { \% Degradation } \\
\text { Efficiency }\end{array}$ \\
\hline 100 & $\mathrm{Cu}_{0.05} \mathrm{Zn}_{0.95} \mathrm{O}$ & 400 & 250 & 4 & $26.36 \%$ \\
100 & $\mathrm{Cu}_{0.05} \mathrm{Zn}_{0.95} \mathrm{O}$ & 500 & 250 & 4 & $35.29 \%$ \\
100 & $\mathrm{Cu}_{0.05} \mathrm{Zn}_{0.95} \mathrm{O}$ & 600 & 250 & 4 & $64.13 \%$ \\
\hline
\end{tabular}

\subsection{Effect of Calcination Temperature on Photocatalytic Activity of Cu0.05Zn0.95O.}

From the Table: 7 it is found that $\mathrm{Cu} 0.05 \mathrm{Zn} 0.95 \mathrm{O}$ shows maximum photocatalytic degradation efficiency. $\mathrm{Cu} 0.05 \mathrm{Zn} 0.95 \mathrm{O}$ was selected to study calcination temperatures effect of photocatalytic degradation efficiency studies on LASER dye. The results are summarized in Table No. 9 and in Figure No. 19.

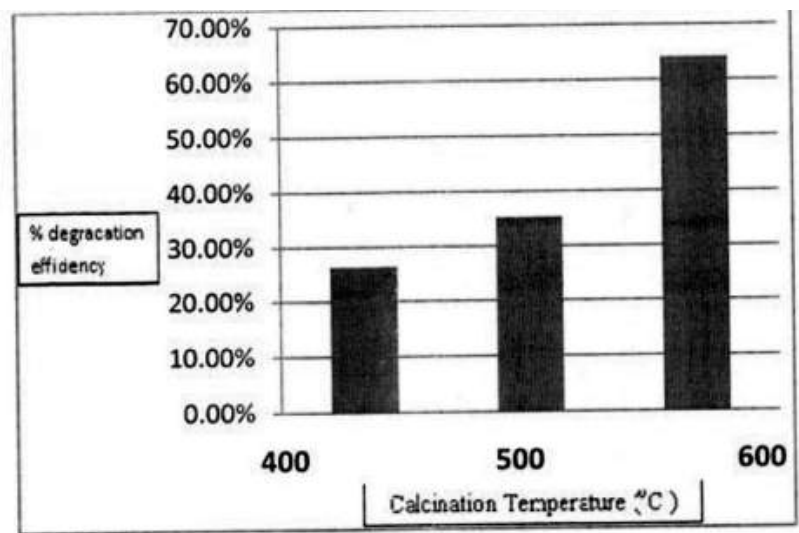

Figure 19. Effect of calcination temperature on degradation of LASER dye solution.

\subsection{Effect of Photo-sensitizers on Pure $\mathrm{ZnO}$ \& Cu $0.05 \mathrm{Zn} 0.95 \mathrm{O}$}

Pure Samples $\mathrm{ZnO} \& \mathrm{Cu}_{0.05} \mathrm{Zn}_{0.95} \mathrm{O}$ are used to study of photosensitizers. The effect of different salts such as $\mathrm{Na} 2 \mathrm{CO} 3, \mathrm{NaCl}$ and $\mathrm{Na} 2 \mathrm{~S} 2 \mathrm{O} 3$ on their photocatalytic activity are studies by varying the amount of this salts. 100 $\mathrm{mL}$ of LASER dye solution $(10 \mathrm{~mL}$ diluted to $1000 \mathrm{~mL})$ was taken in batch photocatalytic reactor, in it $250 \mathrm{mg}$ of pure $\mathrm{ZnO}$ and different amount $(250 \mathrm{mg}, 500 \mathrm{mg}$ and 1000 mg) of salts such as $\mathrm{NaCl}, \mathrm{Na} 2 \mathrm{CO}_{3}$ and $\mathrm{Na} 2 \mathrm{~S} 2 \mathrm{O} 3$ was added and irradiated under sunlight for 4 hrs. Then the solution was filter through what-man filter paper No. 42 . The clear solution was used to measure its absorption on UV-Visible spectrophotometer-1601 SHIMADZU. It is seen that photocatalytic degradation efficiency changes with use of different amount of different salts as photosensitizers. The results are shown in Table No. 10.

It is seen that the different photo-sensitizers shows different effect on photocatalytic degradation efficiency. $\mathrm{NaCl}$ and $\mathrm{Na} 2 \mathrm{CO} 3$ show positive effect, while $\mathrm{Na} 2 \mathrm{~S} 2 \mathrm{O} 3$ shows negative effect. As amount of photo-sensitizer increases photocatalytic property of $\mathrm{NaCl}$ and $\mathrm{Na} 2 \mathrm{CO} 3$ increases and photocatalytic property of $\mathrm{Na} 2 \mathrm{~S} 2 \mathrm{O} 3$ decreases. 
Table 10. Effect of Photo-sensitizers on pure $\mathrm{ZnO}$ and $\mathrm{Cu}_{0.05} \mathrm{Zn}_{0.95} \mathrm{O}$

\begin{tabular}{lllll}
\hline $\begin{array}{l}\text { Volume of LASER } \\
\text { dye solution }(\mathbf{m L})\end{array}$ & $\begin{array}{l}\text { Photo-catalyst }+ \text { Photo-sensitizers } \\
\text { Amount }(\mathbf{m g})\end{array}$ & $\begin{array}{l}\text { Irradiation Time } \\
(\text { hrs })\end{array}$ & $\begin{array}{l}\text { \% Degradation } \\
\text { Efficiency }\end{array}$ \\
\hline \multirow{3}{*}{100} & & 250250 & & 49.34 \\
& $\mathrm{ZnO}+\mathrm{NaCl}$ & $250+500$ & 4 & 57.91 \\
& & $250+1000$ & & 65.33 \\
100 & $250+250$ & & 42.85 \\
& & $250+500$ & 4 & 71.59 \\
& $\mathrm{ZnO}+\mathrm{Na} 2 \mathrm{CO} 3$ & $250+1000$ & & 78.31 \\
100 & & $250+250$ & & 3.67 \\
& & $250+500$ & 4 & 0.89 \\
100 & $\mathrm{ZnO}+\mathrm{Na} 2 \mathrm{~S} 2 \mathrm{O} 3$ & $250+1000$ & & 1.00 \\
100 & & $250+1000$ & 4 & 20.32 \\
100 & $\mathrm{Cu}_{0.05} \mathrm{Zn}_{0.95} \mathrm{O}+\mathrm{NaCl}$ & $250+1000$ & 4 & 27.33 \\
\hline
\end{tabular}

\section{Conclusion}

The copper doped zinc oxides $\left(\mathrm{Cu}_{\mathrm{x}} \mathrm{Zn}_{1-\mathrm{x}} \mathrm{O}\right.$; where $\mathrm{x}=0.05$, $0.1,0.15,0.2$ ) was synthesized by co-precipitation method. The doping was confirmed by XRD and FTIR studies. The photocatalytic degradation of LASER dye solution using $\mathrm{Cu}_{\mathrm{x}} \mathrm{Zn}_{1-\mathrm{x}} \mathrm{O}$ (where $\mathrm{x}=0.05,0.1,0.15,0.2$ ) photo-catalyst showed that $\mathrm{Cu}_{0.05} \mathrm{Zn}_{0.95} \mathrm{O}$ shows better activity than other synthesized catalyst. The photocatalytic degradation of LASER dye solution using $\mathrm{Cu}_{0.05} \mathrm{Zn}_{0.95} \mathrm{O}$ photo-catalyst calcined at various temperature $\left(400,500\right.$ and $600^{\circ}$ C) showed sample calcined at $600{ }^{\circ} \mathrm{C}$ shows maximum efficiency. It is also found that the different photosensitizers shows different effect on photocatalytic degradation efficiency. $\mathrm{NaCl}$ and $\mathrm{Na}_{2} \mathrm{CO}_{3}$ shows positive effect, while $\mathrm{Na}_{2} \mathrm{~S}_{2} \mathrm{O}_{3}$ shows negative effect. As amount of photosensitizer increases photocatalytic property of $\mathrm{NaCl}$ and $\mathrm{Na}_{2} \mathrm{CO}_{3}$ increases and photocatalytic property of $\mathrm{Na}_{2} \mathrm{~S}_{2} \mathrm{O}_{3}$ decreases. Among the all photo-sensitizers $\mathrm{Na}_{2} \mathrm{CO}_{3}$ is act best photo-sensitizer for both $\mathrm{ZnO}$ and $\mathrm{Cu}_{0.05} \mathrm{Zn}_{0.95} \mathrm{O}$.

\section{References}

[1] Aleksandra B. Djurisic, Xinyl Chen, Yu Hang Leung and Alan Man Ching Ng (2012). ZnO Nanostructures: growth, properties and applications. Journal of Materials Chem, 22, 6526-6535.

[2] Celine J. Bodson et.al. (2014). P-Doped Titania Xerogels as efficient UV- Visible photo-catalyst (2014). Journal of Materials Science and Chemical Engineering, 2, No. 8.
[3] E A Meulenkamp (2017). Synthesis and Growth of $\mathrm{ZnO}$ nanoparticles. The Journal of Physical Chemistry C-2017 121 27, 14879-14887.

[4] M D Mccluskey (2009). Defects in ZnO: Journal of Applied Physics: 106, No. 7.

[5] Z L Wang (2004). Zinc Oxide nanostructures: growth, properties and applications (2004). J. Phys, Condens, Matter 16, R829-R858.

[6] Inorganic Quantitative Analysis by Vogel, $3^{\text {rd }}$ edition, ELBS Publishers.

[7] Sorna Prema Rajendran and kandasamy Sengodan (2017). Synthesis and Characterization of $\mathrm{ZnO}$ and $\mathrm{FeO}$ nano particles using sebania grandiflora leaf extract as reducing agent. Journal of nanoscience, Volume 2017, Article ID 8348507.

[8] H. Hayashi and Y. hakuta (2010). Hydrothermal synthesis of metal oxide nanoparticles in super critical water, Materials, 3, no-7, 3794-3817.

[9] H. Kumar and R. Rani (2013). Structural and optical characterization of $\mathrm{ZnO}$ nanoparticles synthesized by micro-emulsion route, International letters of Chemistry, Physics and Astronomy, 19, 26-36.

[10] Z. Meng and Z. Juan (2008). Waste water treatment by photocatalytic oxidation of nano-ZnO. Global Environmental Policy in Japan, 12, 1-9. 